\title{
EVALUATION OF NON-MOTORIZED USE IN GRAND TETON NATIONAL PARK Phase II: Post PathWay CONSTRUCTION 2012
}

\author{
PAT MCGOWEN $\uparrow$ REBECCA GLEASON \\ WESTERN TRANSPORTATION INSTITUTE $\uparrow$ MONTANA STATE UNIVERSITY
}

\section{$\downarrow \quad$ INTRODUCTION}

The 2006 Transportation Plan for Grand Teton National Park proposed 22.5 miles of multi-use pathways outside the road to enhance safety and mobility for travelers using non-motorized modes of transportation in the most visited and developed areas of the park. (Grand Teton National Park Transportation Plan 2006, 2007). Construction of the Phase I Pathway, a 7.7-mile segment between Dornan's Junction and South Jenny Lake Junction along Teton Park Road began in June 2008 (Figure 1). This report summarizes research conducted by the Western Transportation Institute at Montana State University before and after this construction occurred. Researchers counted non-motorized travelers, primarily bicyclists and pedestrians, and administered surveys to learn about visitor perceptions regarding the conditions for nonmotorized travel in the park. The primary purpose of this research was to compare the conditions before and after Phase I Pathway was constructed. These results also offer a "point-in-time" glimpse of current non-motorized usage of this region of the park.

\section{Non-Motorized Traveler Counts}

Researchers conducted counts of nonmotorized users over a three-day period (Friday, Saturday and Sunday) during four time-periods (Table 1):

- The first count was conducted from April 27 through 29, 2007, which represented use during the pre-season closure of Teton Park Road to motor vehicles. The annual tradition of biking the road on the last weekend prior

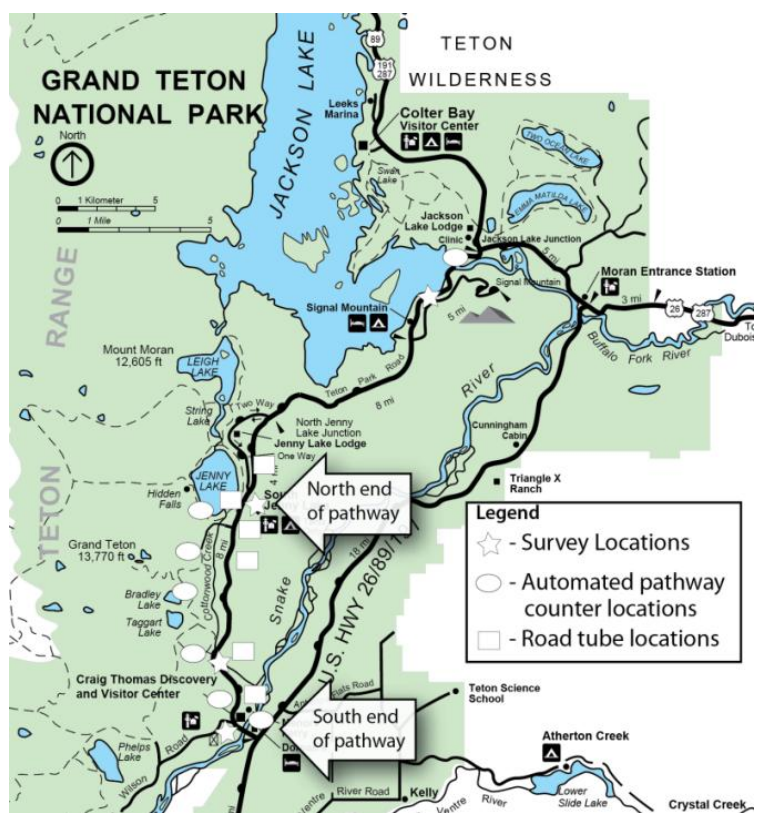

Figure 1: Location of Phase I Pathway

to the seasonal road opening resulted in high usage during this data collection period and is not considered typical non-motorized use during the season.

- Researchers returned on August 24 through 26, 2007. The August data are intended to estimate typical non-motorized use during the peak visitation period of May through September.

- After the Phase I Pathway was completed, data were collected again in August 2010 to 
compare with the August 2007 data. Counts were made on August 20 through 22, 2010.

- To capture the peak usage, another data collection trip was completed on July 22 through 24, 2011. Although the August data provided a before-after comparison, the July data indicate the highest use of the summer season.

Table 1: Average Daily Directional Counts for NonMotorized Travel

\begin{tabular}{lccc}
\hline $\begin{array}{l}\text { Day of } \\
\text { Week }\end{array}$ & $\begin{array}{c}\text { Pre- } \\
\text { Construction } \\
\text { August 2007 }\end{array}$ & $\begin{array}{c}\text { Post- } \\
\text { Construction } \\
\text { August 2010 }\end{array}$ & $\begin{array}{c}\text { Post- } \\
\text { Construction } \\
\text { July 2011 }\end{array}$ \\
\hline Friday & 10 & 116 & 127 \\
Sat./Sun. & 18 & 113 & 155 \\
\hline
\end{tabular}

The count data show that non-motorized usage during a typical week in August increased significantly after the pathway was constructed. With the pathway available, there was slightly more usage in July 2011 than August 2010.

\section{Non-Motorized Traveler Survey}

Researchers surveyed travelers at the same times and locations where they conducted the traveler counts. A total of 279 surveys were completed in April 2007; 58 surveys were completed in August 2007; 180 surveys were completed in August 2010; and 192 surveys were completed in July 2011. The surveys asked park visitors where they began their non-motorized trip and where they were headed, the purpose of the trip, some general demographic questions, their experience and opinions regarding park facilities, and the nature of any interactions they might have had with wildlife. Non-motorized user survey results collected after the pathway was constructed were compared to results prior to pathway construction. Based on this comparison, the average non-motorized user after pathway construction:
- Felt safer,

- Was more satisfied with non-motorized travel,

- Was older,

- Was less likely to be travelling alone,

- Was more likely to be traveling with children, and

- Was more likely to be non-local.

In addition, non-motorized users had a more even distribution by gender after the pathway was constructed. The presence of the pathway did not have much impact on the trip purpose, whether users entered the park in a motorized vehicle, or their parking satisfaction.

\section{$\uparrow \quad$ SUMMARY}

The construction of the Phase I Pathway has increased non-motorized travel nearly ten-fold. The pathway has also improved the visitor experience, as non-motorized travelers feel safer and are more satisfied with non-motorized travel options in the park. The change in user type also indicates that the presence of a separated pathway attracts more types of individuals to use non-motorized modes of travel.

\section{$\downarrow \quad$ Literature Cited}

Grand Teton National Park Transportation Plan/Final Environmental Impact Statement, National Park Service, U.S. Department of the Interior, September 2006.

Grand Teton National Park Transportation Plan/Environmental Impact Statement/ Record of Decision, National Park Service, U.S. Department of the Interior, March 2007. 